ment, should be segregated in an inviolable reserve; and that legislation similar to that in force in New Guinea for the protection of natives should be imposed in their interest. Watering depots for pearlers on the coast of Arnhem Land should be abolished. The policy of administering native justice should be revised; the police should not be allowed to act as protectors; and special courts for the aborigines should be established. It is recommended further that the Commonwealth Government should set up a Department of Native Affairs under a trained protector and staffed by men trained to apply anthropological methods; while eventually the administration of native affairs throughout Australia should be brought under one control. The Arnhem Land natives should not be permitted to leave the reserve, and missions should be requested to remove their stations to the outskirts of the reserve to prevent the entry of outside influence.

Setring aside the larger question of the unification of control of aboriginal affairs throughout Australia, for which much is to be said, Dr. Thomson's recommendations represent the absolute minimum of immediate and urgent reform essential for the preservation of the aborigines of the Northern Territories. Mr. McEwen, Commonwealth Minister of the Interior, is reported to have expressed the view that, as it is inevitable that sooner or later the aborigines must come into contact with civilization, they should be prepared for it. Apparently he accepts an opinion attributed to "some anthropologists" that the segregation of tribalized natives "is undesirable and impracticable". Without a more precise statement of its authority, such an opinion carries little conviction; and it is contrary to the views of anthropologists most competent to speak. How far segregation is practicable and likely to be beneficial depends upon the will of the Australian people to ensure that full effect shall be given to that policy, which past experience shows alone to be capable of affording the aboriginal an opportunity to survive. Segregation does not necessarily entail a state of stagnation in which the aboriginal tribe is a museum piece. When once conditions favourable, and indeed essential, to the continued existence of the aborigines have been secured, it will be possible to plan their future and guide development along lines consistent with their character and tradition.

\section{Segregation in Polish Universities}

NEARLY one thousand outstanding scholars in leading universities in the United States have signed an open letter to their colleagues in some of the universities of Poland, where Jewish students are now segregated from their fellows, and repeated acts of violence are reported against them and Jewish professors. It is realized that the university authorities are faced with great difficulties on account of religious and racial differences, but to bring these conditions of strife into the classrooms and laboratories by adoption of a policy of segregation violates the principle of intellectual freedom upon which university life must be based. "Such discrimination", the signatories protest, "seems to us alien to the spirit of academic freedom and of the free co-operation in the pursuit of knowledge that is so essential to the world of scholarship". The distinguished members of the faculties of Polish institutions of higher learn. ing who have raised their voices against this discrimination will, it is hoped, be encouraged by this support of their American colleagues to continue their efforts to maintain the high tradition of such institutions in the free republic of scholarship. Sympathy with suffering, and sensitiveness to injustice, are attributes which distinguish man from all his fellow creatures; and any deliberate action which evokes them cannot be other than a reversion to primitive instincts. In this twentieth century it is depressing to see the law of the jungle being accepted and applied to secure racial and national domination, when such great powers and opportunities exist for the progressive evolution of man's higher nature. Those of us who believe in a nobler destiny for the human race than has yet been reached find a certain amount of comfort in the dismay expressed by American scholars at the extension to Poland of a spirit of intolerance foreign to every principle for which a university should stand.

\section{Institute of Economic and Social Research}

ANNOUNCEMENT is made of the formation of a new Institute of Economic and Social Research. Sir Josiah Stamp is to be the first president of the Institute, and Prof. N. F. Hall, professor of political economy in the University of London (University College), is to be director. Among the functions of the Institute are the carrying out of research, either by its own staff or by others temporarily associated with it, into the facts and problems of contemporary human society, and the publication of the results of researches, subject to adequate safeguards for the impartial and scientific character of these publications. Financial support for the Institute is being provided by the Sir Halley Stewart Trust, the trustees of the late Lord Leverhulme, the Pilgrim Trust and the Rockefeller Foundation. An annual income has been guaranteed of $£ 10,000$ for five years, and $£ 5,000$ for two years after. The offices of the Institute will be at 32 Gordon Square, London, W.C.1.

\section{Physical Society's Exhibition}

THe Catalogue of the Physical Society's Exhibition, held in the Imperial College of Science and Technology on January 4, 5 and 6, covers 226 pages, has many illustrations and is well arranged. The paging is on the bottom edge of the page, the number of the stall on the top outer corner and the name of firm exhibiting on the top inner corner. It is divided into two sections, Trade (177 pages) and Research (36 pages), and an alphabetical list of exhibitors in each section is provided which gives also the number of the stall. A four-page index of the instruments exhibited with indication of the pages on which they are described is also provided. Reference to the catalogue is therefore easy and quick. New exhibits are indicated in the catalogue by an asterisk and on 